Research Article

\title{
Analysis of the Influence Characteristics of the Support Stability of a Fully Mechanized Coal Mining Face under the Hard Roof Mining Pressure
}

\author{
Jiaxin Dang $\mathbb{D}^{1,2}$ Min Tu $\mathbb{D}^{1,2}$, Xiangyang Zhang $\mathbb{D}^{1,2}$ and Qingwei Bu $\mathbb{C}^{2,3}$ \\ ${ }^{1}$ School of Mining Engineering, Anhui University of Science and Technology, Huainan 232001, China \\ ${ }^{2}$ Key Laboratory of Coal Mine Safety and Efficiently Caving of Ministry of Education, \\ Anhui University of Science and Technology, Huainan 232001, China \\ ${ }^{3}$ School of Mining and Coal, Inner Mongolia University of Science and Technology, Baotou 014010, China \\ Correspondence should be addressed to Min Tu; mtu@aust.edu.cn
}

Received 7 September 2021; Accepted 4 October 2021; Published 29 October 2021

Academic Editor: Gan Feng

Copyright (C) 2021 Jiaxin Dang et al. This is an open access article distributed under the Creative Commons Attribution License, which permits unrestricted use, distribution, and reproduction in any medium, provided the original work is properly cited.

The conditions of the hard roof in my country vary greatly, ranging from a few meters to tens of meters or even hundreds of meters in thickness. The coal reserves under the hard roof account for about one-third of the total reserves. At present, nearly $40 \%$ of fully mechanized mining faces that belong to the hard roof working face has the problem of mining in the hard roof working face. This has a serious impact on the load-bearing stability of the fully mechanized support, and it is urgent to solve the problem of strong underground pressure dynamic disaster under the condition of the hard roof. Based on the research background of 11129 working face in Zhangji Coal Mine in Huainan, this paper constructs a mechanical model of the interaction between the cantilever beam of the hard roof of the stope and the support and then the force distribution equation of the bearing capacity of the supports at different positions of the roof during the periodical rotation of the working face is obtained, which is combined with numerical simulation and engineering site to verify. The research results show that the bearing stability of the support is significantly affected by factors such as the buried depth $H$, the roof elastic modulus $E$, the roof thickness $h$, and the roof cantilever length $l_{0}$, but most of the influencing factors belong to the geological occurrence conditions of the coal seam itself. Presplit blasting of the roof in advance can effectively destroy the integrity of the roof itself and reduce the periodic breaking distance, thereby improving the apparent environment of roof rock pressure and reducing the force on the working face support. According to the specific geological environment of the 11129 working face, the cutting plan of the cut hole is given out, along the groove $0 \sim 200$ and $200 \sim 700 \mathrm{~m}$ of the concrete presplitting blasting. The stent force of the top-cutting section fluctuates in the range of $3360.8-4347.9 \mathrm{kN}$ in the range of control top distance $(5275 \sim 6175 \mathrm{~mm})$. The load-bearing pressure of the stent before top-cutting is about 1.8 times of that after top-cutting. The pressure distribution of the hydraulic support in the numerical simulation stope is approximately " $\Lambda$ " in the middle and the low on the two sides. The simulated value is slightly smaller than the theoretical calculation value. The reason is that the goaf is backfilled during the simulation process, and the roof has a certain ability to bear the load. Real-time understanding of the "roof-support" mechanical relationship can effectively ensure the safe and efficient mining of the 11129 working face and also provide experience for the subsequent mining of group B coal in the later period.

\section{Introduction}

The conditions of hard roofs in my country vary greatly, with thicknesses ranging from tens of meters to hundreds of meters. The reserves of coal resources under the hard roofs account for about one-third of the total reserves. At present, nearly $40 \%$ of fully mechanized mining faces belong to hard roofs. In the working face, more than $50 \%$ of the mining areas across the country have problems with the mining of hard roof working faces. This has a serious impact on the load-bearing stability of the fully mechanized support, and it is urgent to solve the problem of strong underground 
pressure dynamic disaster under the condition of hard roof. The safe bearing of fully mechanized mining support is extremely important for the safe and efficient mining of coal face. The working state of support is required to adapt to the coal rock bearing structure of coal face for ensuring the safety and stability of support bearing. Therefore, conducting in-depth analysis on the bearing stability of fully mechanized mining support under strong mining pressure of the hard roof is necessary [1-5].

At present, many scholars consider the roof surrounding rock and the support as a whole to conduct research. The mechanical effects of different deflection changes on the support during the rotation of the roof are different, and many fruitful results have been achieved in reasonably determining the working resistance of the stope hydraulic support. Wang et al. [6] investigated the roof structure characteristics and reasonable bearing capacity of supports in fully mechanized face with large mining height by combining theoretical analysis with field measurement. They proposed the concept and discrimination method of direct roof key layer. Wang et al. [7] took the 31402 working face of the Ulan Mulun coal mine as the engineering background. They studied the four failure modes of the coal seam under different stress environments and obtained the vertical deformation of the coal wall and the effect on the coal wall on the basis of the principle of minimum potential energy. The actual roof load and physical simulation experiment of coal wall stability analysis under different support rigidity conditions are designed, and the simultaneous monitoring of coal wall horizontal and vertical deformation is realized. Wang et al. [8] used theoretical analysis and numerical simulation methods to study the determination of the reasonable working resistance of the super large mining height hydraulic support for the occurrence conditions of hard and thick coal seams in Jinjitan Coal Mine. They concluded the occurrence of the control of the coal slab sliding instability, which is the crucial protection force of hydraulic support. Pang et al. [9] explored the influence of roof failure and coal wall slabs on the stress path by analyzing the relationship between the supporting force and the protective force. This process is performed to control the longwall mining surrounding rock with large mining heights combined with the coal seam conditions of Jinjitan Coal Mine. They proposed a two-factor control method for calculating the working resistance of a hydraulic support. Bai et al. [10] used the analysis of coal wall stability in the 14101 fully mechanized caving face of Majialiang Coal Mine as the background. They conducted theoretical analysis to study the influence of support resistance, coal wall protection pressure, main roof fracture position, and mining height on coal wall deformation. With the increase in supporting resistance, the rotation angle of the main roof decreases linearly. With the increase in the supporting resistance and protective force provided by the protective surface, the maximum deformation of the coal wall decreases linearly. Das [11] took the Indian geological longwall face engineering as the background to analyze the geological, physical, and mechanical rock characteristics and the characteristics of the roof rock of the coal measure during mining. This study highlights the characteristics of rock fragmentation and caving to contribute to the development of roof rock classification system. Lou et al. [12] verified and evaluated the adaptability of the support and surrounding rock control through numerical simulation and large-scale stope similar simulation experiments. They determined the reasonable working resistance of the support in a fully mechanized mining face with a large mining height of $6.0 \mathrm{~m}$. The results show that the determination of the working resistance of the large mining height fully mechanized support should meet the prerequisite of the control of the surrounding rock of the stope, such as the roof and the coal wall, and ensure a good position of the support. Yin [13] divided the relationship between the support and surrounding rock in the coal mining cycle into two stages in accordance with the given deformation, load, and different roof motion characteristics. This process is performed to reveal the dynamic mechanism of hydraulic support and surrounding rock. The theoretical analysis and field measurement results reveal the dynamic mechanism of the fully mechanized mining support and surrounding rock in the dual-cycle process.

At present, many scholars have conducted a lot of analysis on the mechanical properties of the deep roof rock mass and have obtained a series of results [14-24]. Good research progress has also been made in the analysis of the bearing stability of the working face support. However, with the continuous advancement of the working face, the site cannot accurately grasp the deflection changes of the roof at different positions during the periodic weighting process, and it cannot accurately grasp the mechanism of the mechanical transfer of the roof to the stope support during the rotating and breaking process. The important reason is that the interaction relationship between the different positions of the top plate and the bracket cannot be accurately judged. Under the action of strong mining pressure from the hard roof of deep wells, past engineering experience or similar working face processing methods are used to determine the reasonable working resistance of the working face support, and the deviation will often be large. Although there are related mechanical models to analyze the interaction between the roof and the support, it still fails to reveal the specific factors affecting the support stability of the working face; the load stability of the support under the strong mining force under the hard roof is not insufficient. Therefore, this article takes the 11129 working face of Zhangji Coal Mine under the Huainan Mining Group as the background and develops the mechanical relationship of the "roof-support" common bearing structure of the working face under the condition of a hard roof. Analytical solutions of the support bearing resistance at different positions of the roof during the periodical weight and rotation of the working face were obtained and verified by numerical simulation and engineering practice, which provided a theoretical basis for safe and efficient mining in deep and hard roof coal mines. 


\section{Overview Analysis of the Hard Roof and Strong Mining Pressure Manifestation Project}

The 11129 working face of Zhangji Coal Mine is $240 \mathrm{~m}$ long and $700 \mathrm{~m}$ buried deep from the ground. The main mining 91 coal has an average thickness of $1.9 \mathrm{~m}$. The main mining seam is a monoclinic structure, which is generally high in the west and low in the east. The dip angle is $2^{\circ} \sim 6^{\circ}$. The direct top lithology is $7 \mathrm{~m}$ thick quartz sandstone, the old top lithology is $8.0 \mathrm{~m}$ thick siltstone, and the direct bottom lithology is $2.5 \mathrm{~m}$ thick mudstone, with an average thickness of $5.2 \mathrm{~m}$. Thick siltstone, with an average thickness and the occurrence of the roof and floor rocks of the coal seam, is shown in Figure 1 .

According to field investigation and analysis, we have the following: (1) Under the condition of hard roof, with the increase of the suspended roof size of the working face, the coal wall and mining roadway of the working face during the roof pressure period appear severe. (2) The working face is large. The size of the suspended roof is accompanied by a large bending and sinking of the roof, which significantly increases the bearing burden of the support. (3) The increased load of the support leads to an increase in the risk of pressing, which is not conducive to the safety control of the roof of the working face.

\section{Analysis of the Mechanical Interaction Relationship of the "Roof-Support" Common Bearing Structure of the Working Face}

Combining with previous studies on the characteristics of mining stress distribution in advance mining face $[25,26]$, the mining stress distribution of coal and rock mass in advance mining face can be divided into three stages: stress reduction zone, stress increase zone, and original rock stress zone. At this time, the roof of the mining space is similar to a cantilever beam structure in the stress reduction zone. The upper boundary is subjected to compression load due to the mining of the stress reduction zone, and the lower boundary is the support resistance. As shown in Figure 2, the stope space after the overlying basic roof is broken. Its own mass and the load of the following rock layer are transmitted to the coal wall and the support through the direct roof. The support and the coal wall jointly bear the quality of the roof rock layer in the small structure of the stope and press forward along the unit width roof cycle. On the basis of the analytical mechanics model, the weight of the coal and rock mass above the working front is taken as the distributed load, and the maximum load $\mathrm{kp}$ is reached at $l_{1}$ in front of the coal wall. The force of the support is analyzed using the deflection and deformation equation of the cantilever beam.

The coordinate system is established with the end of the cantilever beam as the origin, and the force analysis of the rectangular cantilever beam is solved by elastic mechanics, which is obtained by the balance equation:

$$
\left\{\begin{array}{l}
\sigma_{x}=\frac{M}{I} y, \\
\sigma_{y}=p(x),
\end{array}\right.
$$

where $M$ is the bending moment of cantilever beam, $\mathrm{kN} \cdot \mathrm{m}$, and $I$ is the moment of inertia of beam section, $b^{3} / 12$.

Among them,

$$
\begin{aligned}
p(x) & =\frac{k p-p_{0}}{l_{1}+l_{0}} x+p_{0}, \\
M & =\int_{0}^{x} p(x) \cdot x \mathrm{~d} x=\frac{k p-p_{0}}{3\left(l_{1}+l_{0}\right)} x^{3}+\frac{p_{0}}{2} x^{2}+C .
\end{aligned}
$$

Here, $C$ is a constant.

Deformation component is

$$
\left\{\begin{array}{l}
\frac{\partial u}{\partial x}=\varepsilon_{x}=\frac{1}{E}\left(\sigma_{x}-\mu \sigma_{y}\right)=\frac{1}{E}\left(\frac{M}{I} y-\mu p(x)\right), \\
\frac{\partial v}{\partial y}=\varepsilon_{y}=\frac{1}{E}\left(\sigma_{y}-\mu \sigma_{x}\right)=\frac{1}{E}\left(p(x)-\mu \frac{M}{I} y\right), \\
\frac{\partial v}{\partial x}+\frac{\partial u}{\partial y}=\gamma_{x y}=\frac{2(1+\mu)}{E} \tau_{x y}=0 .
\end{array}\right.
$$

Equation (3) integrates $x$ and $y$ to obtain the following:

$$
\begin{aligned}
u= & \frac{y}{I E}\left[\frac{k p-p_{0}}{12\left(l_{1}+l_{0}\right)} x^{4}+\frac{p_{0}}{6} x^{3}+C x\right]-\frac{\mu}{E}\left[\frac{k p-p_{0}}{l_{1}+l_{0}} x^{2}+p_{0} x\right] \\
& +f_{1}(y), \\
v= & \frac{y}{E}\left(\frac{k p-p_{0}}{l_{1}+l_{0}} x+p_{0}\right)-\frac{\mu y^{2}}{2 E I}\left[\frac{k p-p_{0}}{3\left(l_{1}+l_{0}\right)} x^{3}+\frac{p_{0}}{2} x^{2}+C\right] \\
& +f_{2}(x) .
\end{aligned}
$$

Among them, $f_{1}$ and $f_{2}$ are the undetermined functions of $y$ and $x$, respectively. Substituting formula (4) into the integral of formula (3), we get

$$
\begin{aligned}
& f_{1}(y)=-\omega y-\frac{k p-p_{0}}{2 E\left(l_{1}+l_{0}\right)} y^{2}+\frac{\mu y^{3}}{6 E I}\left[\frac{k p-p_{0}}{l_{1}+l_{0}} x^{2}+p_{0} x\right]+u_{0}, \\
& f_{2}(x)=\omega x-\frac{1}{E I}\left[\frac{k p-p_{0}}{60\left(l_{1}+l_{0}\right)} x^{5}+\frac{p_{0}}{24} x^{4}+\frac{C}{2} x^{2}\right]+v_{0} .
\end{aligned}
$$

The constraints are as follows: 


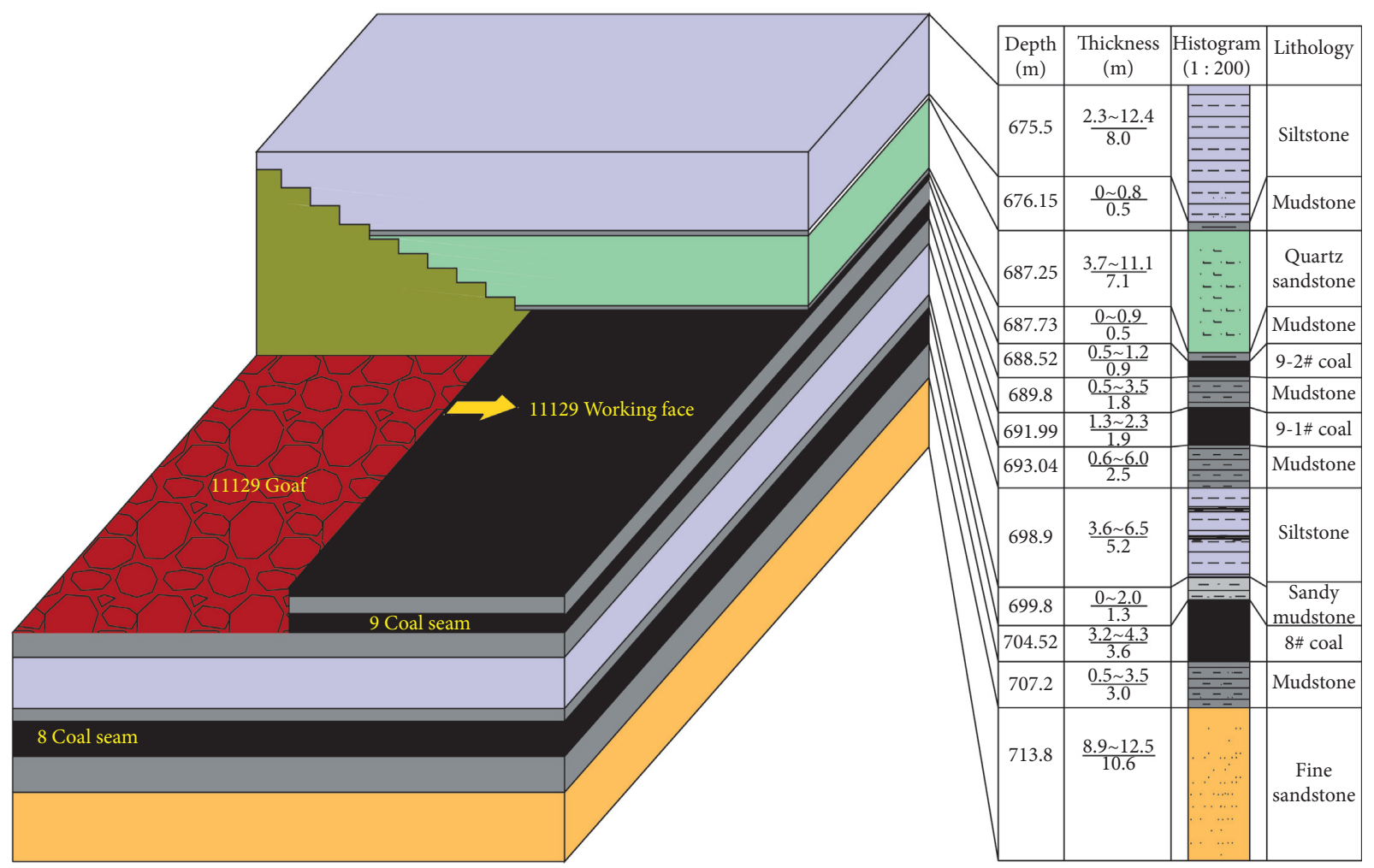

FIGURE 1: Comprehensive histogram of Zhangji mine's mining face.
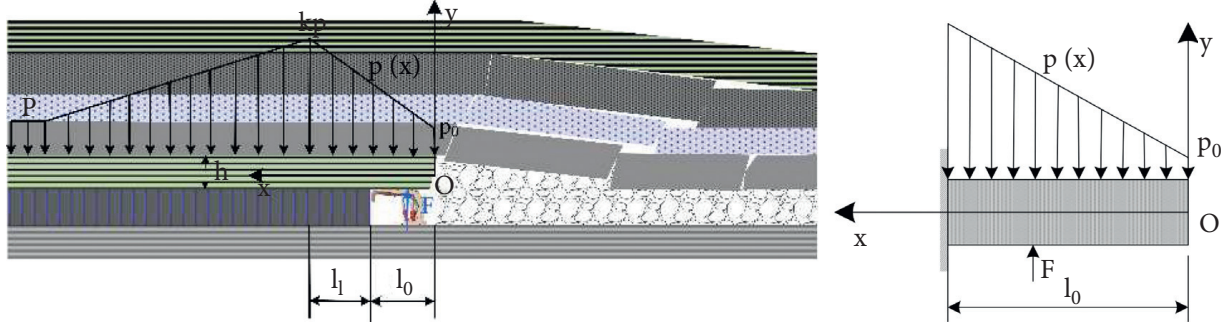

FIgURE 2: Mechanical model of the force distribution on the roof.

$$
\begin{aligned}
&(M)_{x=0}=0, \\
&(u)_{\substack{x=l_{0} \\
y=0}}=0, \\
&(v)_{\substack{x=l_{0} \\
y=0}}=0, \\
&\left(\frac{\partial v}{\partial x}\right)_{x}=l_{0}=0 . \\
& y=0
\end{aligned}
$$

$$
\left\{\begin{array}{l}
C=0 \\
u_{0}=\frac{\mu}{E}\left(\frac{k p-p_{0}}{2\left(l_{1}+l_{0}\right)} l_{0}^{2}+p_{0} l_{0}\right) \\
v_{0}=-\frac{1}{E I}\left[\frac{k p-p_{0}}{15\left(l_{1}+l_{0}\right)} l_{0}^{5}+\frac{p_{0}}{8} l_{0}^{4}+\frac{C}{2} l_{0}^{2}\right] \\
\omega=\frac{1}{E I}\left[\frac{k p-p_{0}}{12\left(l_{1}+l_{0}\right)} l_{0}^{4}+\frac{p_{0}}{6} l_{0}^{3}+C l_{0}\right] .
\end{array}\right.
$$

We derive the cantilever beam deflection equation: 


$$
v=\frac{1}{E I}\left[-\frac{k p-p_{0}}{60\left(l_{1}+l_{0}\right)} x^{5}-\frac{p_{0}}{24} x^{4}+\left(\frac{k p-p_{0}}{12\left(l_{1}+l_{0}\right)} l_{0}^{4}+\frac{p_{0}}{6} l_{0}^{3}\right) x-\left(\frac{k p-p_{0}}{15\left(l_{1}+l_{0}\right)} l_{0}^{5}+\frac{p_{0}}{8} l_{0}^{4}\right)\right] .
$$

At present, the rigidity range of the support line [27] is $100 \sim 600 \mathrm{kN} / \mathrm{m}$, the rigidity range is $10 \sim 80 \mathrm{MPa} / \mathrm{m}$, and the support force is as follows:

$$
F=K A v,
$$

where $K$ is the stent stiffness, $\mathrm{MPa} / \mathrm{m}$, and $A$ is the holder supporting area, $\mathrm{m}^{2}$.

\section{Analysis of the Factors Influencing the Bearing Stability of the Working Face Support}

The force effect of fully mechanized support is mainly related to factors, such as stress concentration factor $k$, buried depth $H$, cantilever roof thickness $h$, cantilever length $l_{0}$, and the distance between the peak support pressure and the coal wall $l_{1}$. In accordance with the mine pressure law and geological structure conditions, the engineering parameter $k$ is 2.5 , the roof elastic modulus $E=33.4 \mathrm{GPa}$, the pseudo roof thickness is $0.5 \mathrm{~m}$, and the direct roof thickness is $7.1 \mathrm{~m}$. The roof thickness $h=7.6 \mathrm{~m}$, periodic collapse step $l_{0}=13 \mathrm{~m}$, the distance from peak bearing pressure to coal wall $l_{1}=10 \mathrm{~m}$, bulk density $\gamma=25 \mathrm{kN} / \mathrm{m}^{3}$, buried depth $H=700 \mathrm{~m}$, and the average load per unit width $p=17.5 \mathrm{MN} / \mathrm{m}$. The rigidity of the ZZ10800/18/38D type support is $25.0 \mathrm{MPa} / \mathrm{m}$, the control distance of the support is $5275-6175 \mathrm{~mm}$, the height is $5.7 \mathrm{~m}$, and the width is $1.5 \mathrm{~m}$. The control roof area $A=5.7 \times 1.5=8.55 \mathrm{~m}^{2}$, and $p_{0}=0.6 p$. For the convenience of drawing, the coal wall is set as the origin of the coordinate, and the reaction force of the support, excluding external and human factors, and different parameters are taken to compare and analyze the pressure change in the support, as shown in Figure 3.

As shown in Figures 3(a) and 3(e), the stronger the advanced mining intensity (the greater the stress concentration factor $k$ ) and the closer the advanced mining stress concentration is to the coal wall cause the upper boundary load of the cantilever beam of the working face to increase. When the coefficient $k$ fluctuates within 1.5-3.0, the bearing resistance of the support varies from $3182 \mathrm{kN}$ to $4931 \mathrm{kN}$. When the distance of $l_{1}$ is increased from $5 \mathrm{~m}$ to $12 \mathrm{~m}$, the resistance of the support at the minimum control distance position is attenuated from $3840.3 \mathrm{kN}$ to $3222.7 \mathrm{kN}$, and the attenuation amplitude is $16 \%$. The resistance of the support at the maximum control distance is attenuated from $4963 \mathrm{kN}$ to $4170.7 \mathrm{kN}$, with an attenuation amplitude of $16 \%$. The resistance of the support at the center of the control distance is attenuated from $4332 \mathrm{kN}$ to $3637.7 \mathrm{kN}$, with an attenuation amplitude of $16 \%$. From the above, it can be known that as the distance from the coal wall increases, the resistance of the support increases, but the attenuation amplitude is basically the same.
As shown in Figures 3(b), 3(c), and 3(d), the greater the buried depth of the coal seam and the greater the elastic modulus $E$ and thickness $h$ of the hard roof of the working face, the greater the impact on the support bearing burden. When the buried depth reaches 300 and $900 \mathrm{~m}$, the bearing resistance of the support within the maximum control distance is 1863 and $5590 \mathrm{kN}$. When the elastic modulus of the roof increases from $8 \mathrm{GPa}$ to $32 \mathrm{GPa}$, the support pressure of the stope gradually decreases from $18,152 \mathrm{kN}$ to $4538 \mathrm{kN}$. With the gradual increase in the thickness of the top plate, the bearing pressure of the support decreased from $40,908 \mathrm{kN}$ to $2157 \mathrm{kN}$. Therefore, understanding the engineering geological parameters of the working face in advance and evaluating the degree of change in the working resistance of the support and its safety and stability are necessary when encountering the hard roof conditions of the working face.

As shown in Figure 3(f), the greater the length of the roof overhang on the working face, the greater the compressive strength of the roof overlying rock, thereby increasing the bearing burden of the support. The length of the cantilever beam was increased from $10 \mathrm{~m}$ to $20 \mathrm{~m}$, and the resistance of the support at the minimum control distance position was increased from $1692.9 \mathrm{kN}$ to $9805.3 \mathrm{kN}$, an increase of 4.8 times. The resistance of the support at the maximum control distance increased from $2157.4 \mathrm{kN}$ to $12928.9 \mathrm{kN}$, an increase of 6 times. The resistance of the support at the center of the control distance increased from $1897.4 \mathrm{kN}$ to $11163.5 \mathrm{kN}$, an increase of 5.9 times. It can be seen from the above that as the length of the cantilever beam increases, the resistance of the support increases geometrically, and the magnitude of the increase is greatest at the position of the maximum control distance. This finding shows that the larger the suspended roof is unconducive to the safe bearing of the support. The presplitting and cutting are necessary to improve the roof pressure appearance environment.

On the basis of the above analysis, the bearing stability of the support is obviously affected by buried depth $\mathrm{H}$, roof elastic modulus $E$, thickness $h$, and roof cantilever length $l_{0}$. However, most of the influencing factors belong to the coal seam's own geological conditions. In the actual mining process, understanding the engineering geological parameters of the working face and evaluating the degree of change in the work resistance of the support and its safety and stability are necessary. When encountering the hard roof conditions of the working face, presplit blasting and cutting of the roof must be conducted in advance to control its periodic weighting distance. This process effectively weakens and destroys the integrity of the hard roof. The roof pressure appearance environment must be improved, and the bearing burden of the working face support must be reduced to ensure the safe and efficient mining of the working face of the underground coal mine. 

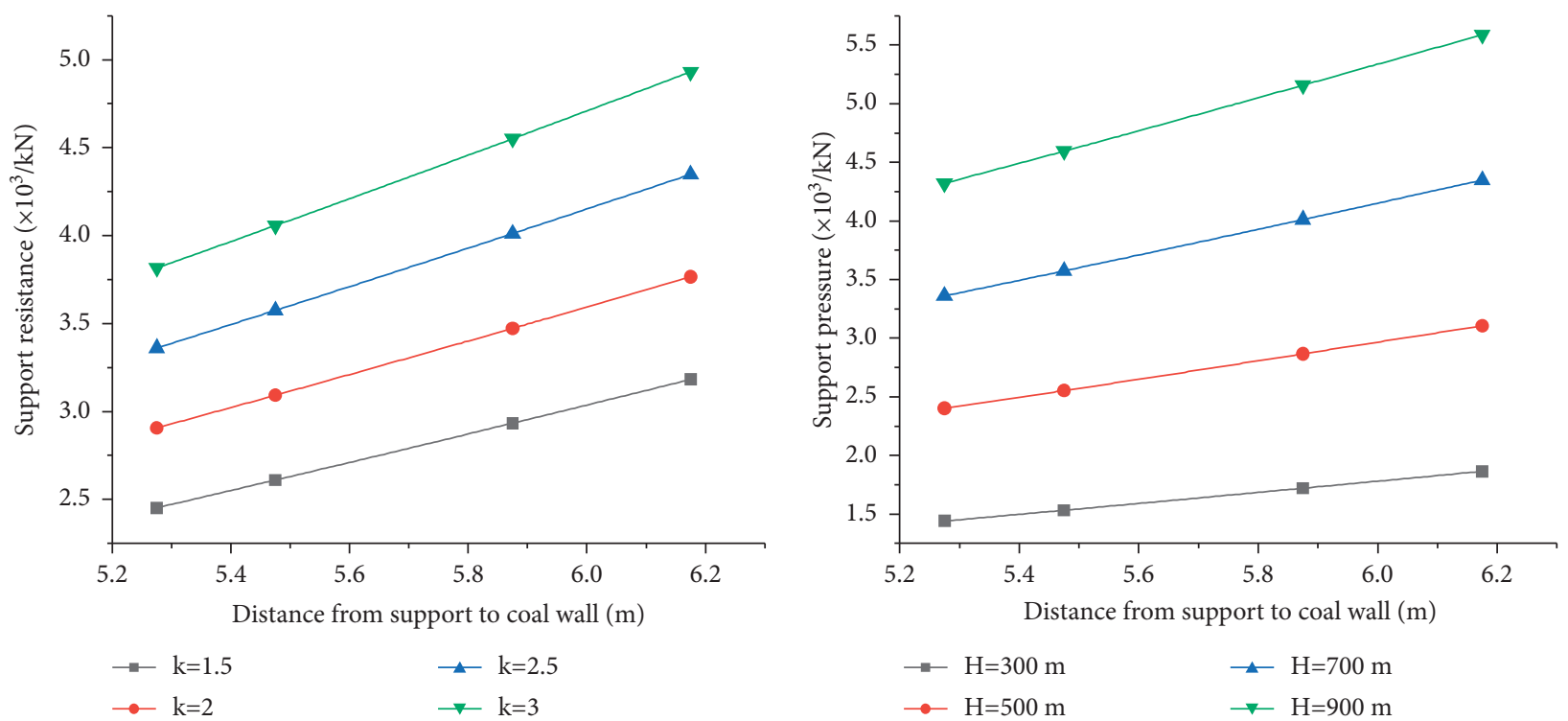

(a)
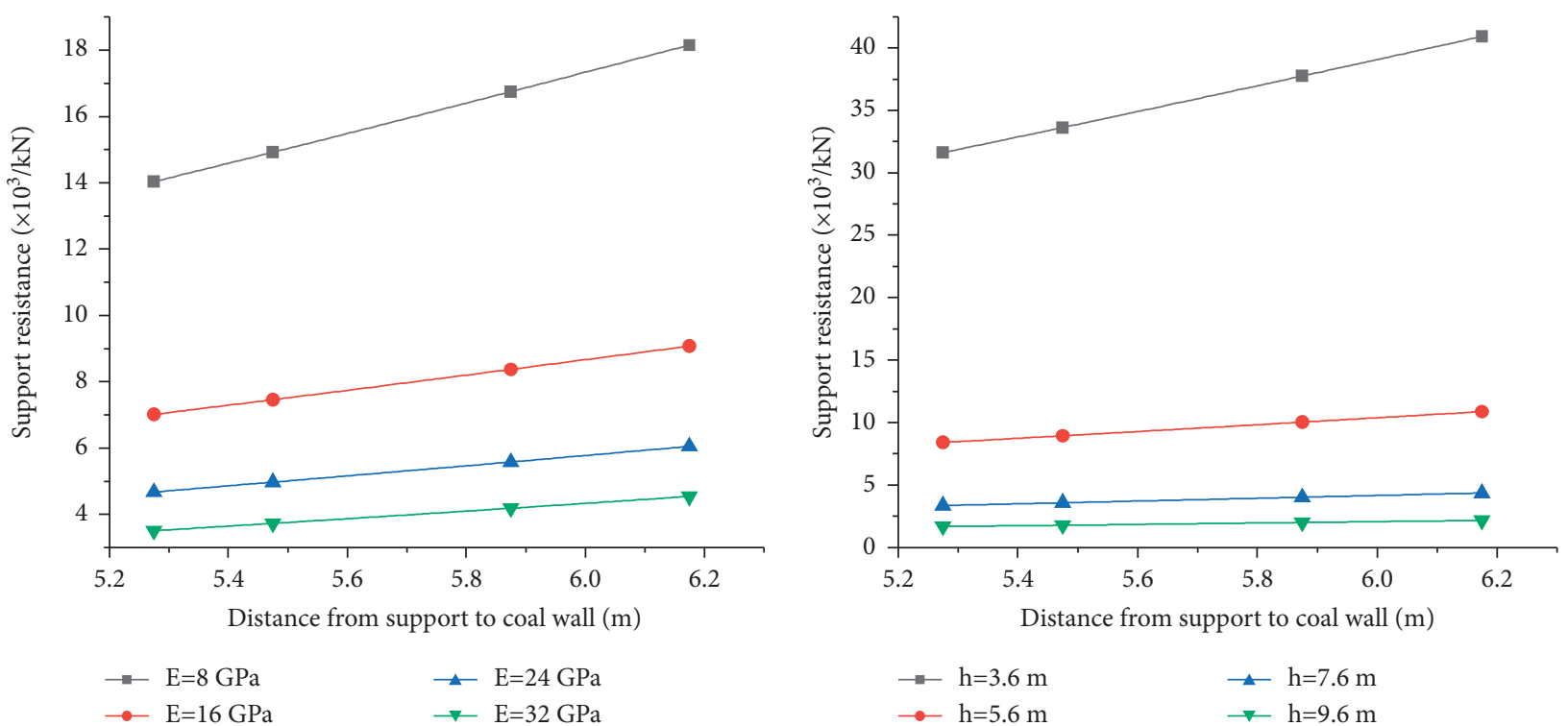

(c)

(d)

Figure 3: Continued. 


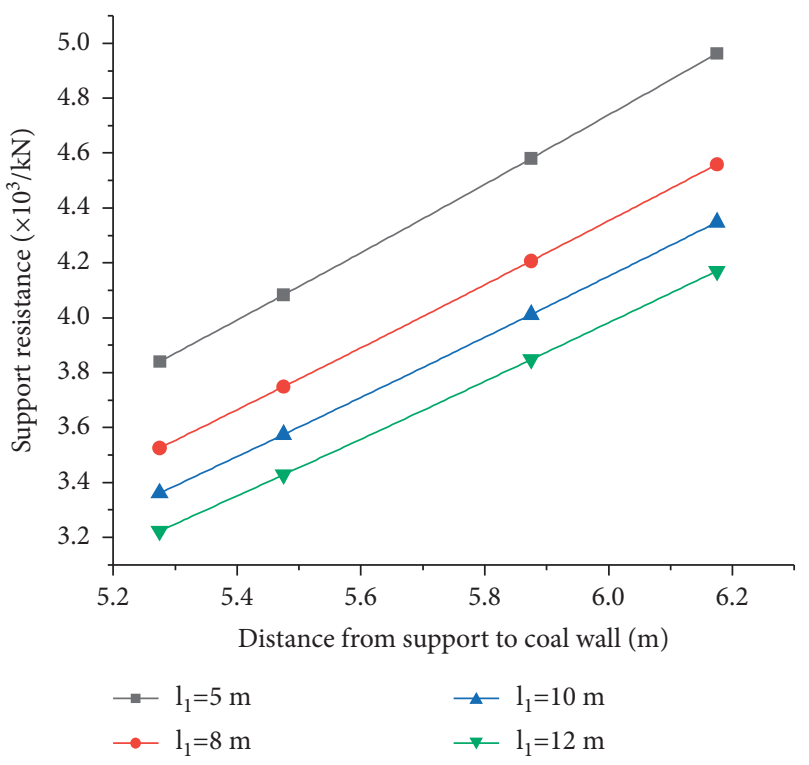

(e)

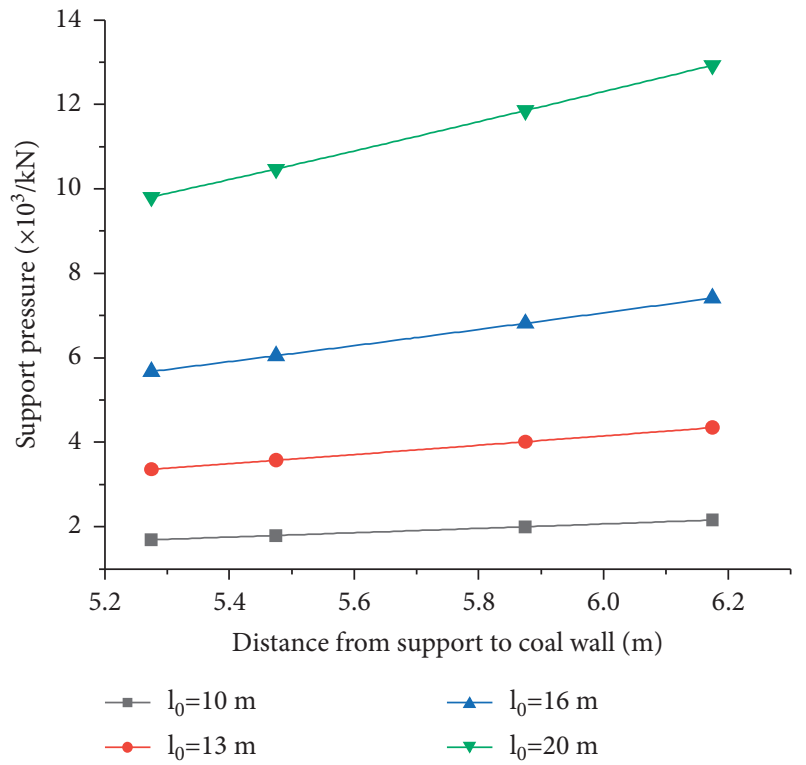

(f)

Figure 3: The change curve of the influence of different factors on the working resistance of the stent. (a) Different stress concentration factors $k$. (b) Different buried depths $H$. (c) Different elastic moduli $E$. (d) Different top plate thicknesses $h$. (e) The distance between the peak of different supporting pressure and the coal wall $l_{1}$. (f) The length of different roof cantilever $l_{0}$.

\section{Zhangji Mine 11129 Working Face Strong Mining Pressure "Roof-Support" Bearing State and Analysis of the Roof Cutting Control Countermeasures}

5.1. Mechanical Relationship Analysis of Support Resistance in the 11129 Working Face of Zhangji Mine. In accordance with the geological conditions of the 11129 working face and the law of mine pressure, the main body of the hard roof is $7.6 \mathrm{~m}$ thick. After deep hole presplit blasting is performed on the roof of the working face, the periodic weighting step of the roof is $12.5-13.5 \mathrm{~m}$ and the average periodic pressing step is $l_{1}=13 \mathrm{~m}$. The upper load $p=17.75 \times 10^{6} \mathrm{~N} / \mathrm{m}$. Formula (9) is used to solve the change relationship of the working resistance of the bracket at different positions, and the diagram of the change of the working resistance of the bracket is drawn, as shown in Figure 4.

As shown in Figure 4, the distribution of the working resistance of the bracket at different positions is analyzed. The roof breaks and collapses periodically during the mining process of the working face. During the breakage and rotation of the roof, the working resistance force at different positions of the roof changes linearly with the working resistance of the stope's hydraulic support. With the distance from the coal wall, the working resistance of the support gradually increases, and the working resistance of the support within the control roof distance range $(5275-6175 \mathrm{~mm})$ is $3360.8-4347.9 \mathrm{kN}$.

Roof cutting control is to conduct deep hole presplitting blasting at different distances in advance of the working face. This process destroys the integrity of the roof and achieves pressure relief and a relatively stable periodic collapse step. In accordance with the analysis of the field measured data of the 11129 working face, the average step length $l_{0}$ $(15.2-17.1 \mathrm{~m})$ of the roof slab collapse before topping is $16 \mathrm{~m}$ on average, and the average of $l_{0}(12.5-13.5 \mathrm{~m})$ after topping is $13 \mathrm{~m}$. The step distance of different parts of the working face is shown in Figure 5. Formula (9) is substituted into formula (9) to compare and analyze the changes in the working resistance of the support at different positions before and after the topping, as shown in Figure 6.

As shown in Figure 5, comparing the pressure step distance between the blasting area and the no blasting area, it can be seen that the pressure step distance of the no blasting area is higher than that of the blasting area, and the pressure step distance of each support in the no blasting area ranges from $15.3 \mathrm{~m}$ to $17.1 \mathrm{~m}$, the average pressure step distance is $16 \mathrm{~m}$, the pressure step distance of each support in the blasting area ranges from $12.5 \mathrm{~m}$ to $13.5 \mathrm{~m}$, and the average pressure step distance is $13 \mathrm{~m}$. The reason is that the no blasting area is affected by the rotational movement of the overlying rock. Owing to the longer rock-breaking block, the smaller rotation angle of the overlying rock-breaking block can be supported by the falling gangue in the goaf, and the phenomenon that the working face cycle is large and the pressure lasts longer. Presplitting blasting destroys the integrity of the overburden and makes it a massive structure. The fractured block of the rock strata is short, the overburden fractured block has a relatively large rotation angle supported by the falling gangue in the goaf, and the pressure step is relatively short. During the pressurization period, the upper and lower support steps in the blasting area and the no blasting area are smaller than other parts. This is not only related to the movement state of the roof before and after the deep hole blasting but also has a direct reason for the advancing speed of the working face due to various reasons. 


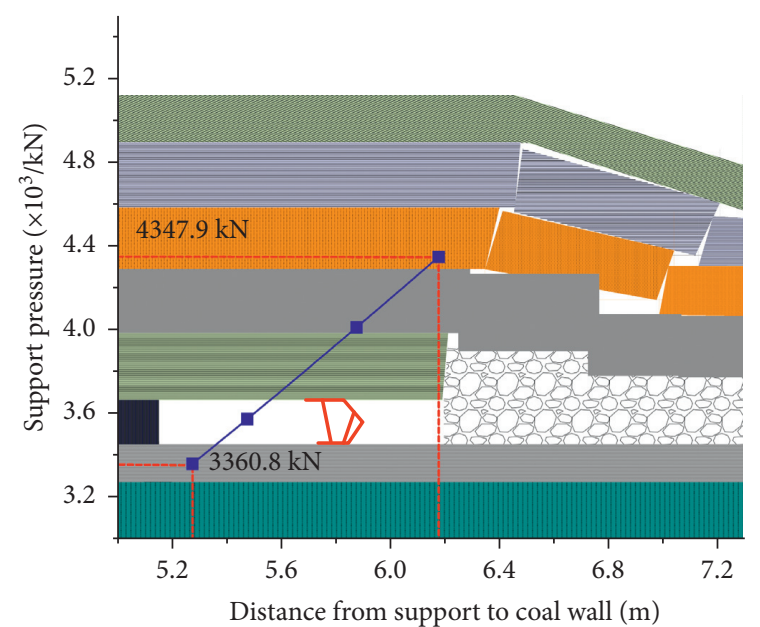

FIGURE 4: Curves of the working resistance of the bracket at different positions.

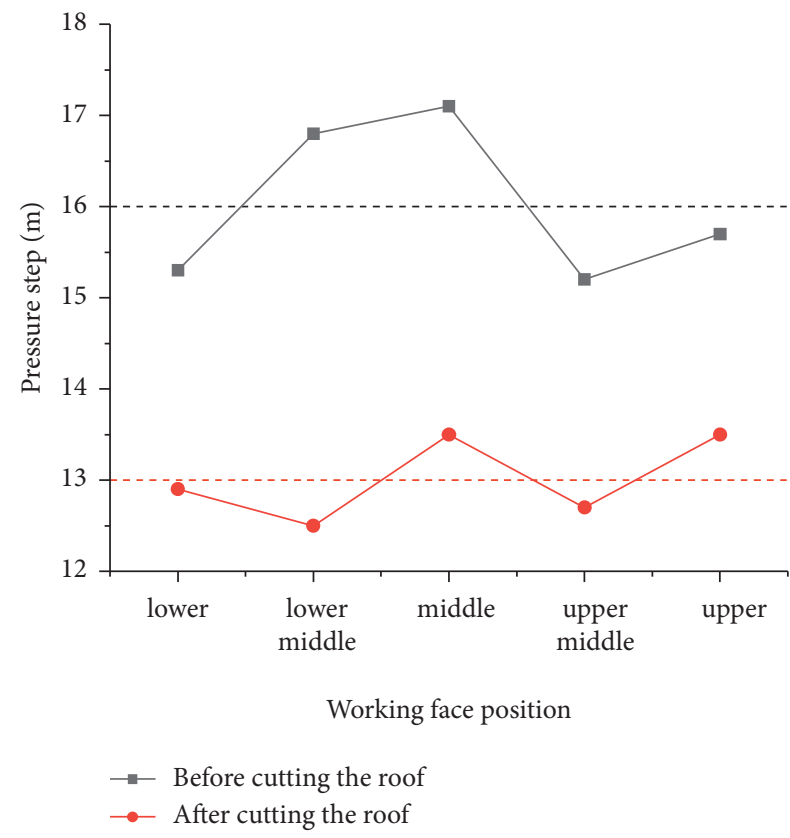

FIGURE 5: Different parts of the working face to press the step distance curve.

As shown in Figure 6, comparing and analyzing the force of the bracket before and after the topping, it can be seen that within the range of the control top distance $(5275 \sim 6175 \mathrm{~mm})$. The average working resistance of the bracket before and after the topping is 6546.5 and $3854.5 \mathrm{kN}$, respectively, and the pressure before and after the topping is about 1.7 times that of the pressure after the topping. With the continuous increase of the distance between the support and the coal wall, the range of the work resistance difference of the stope support gradually increases and the support load increases. Therefore, the advanced deep hole presplitting blasting can effectively reduce the support work resistance and improve the stope working environment.

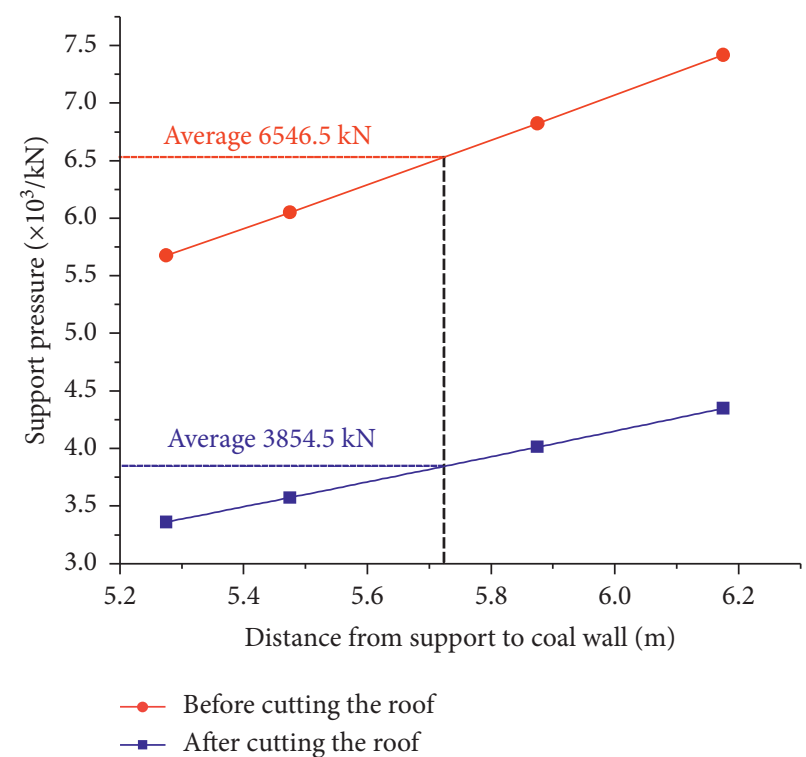

FIGURE 6: Change curve of the working resistance of the support before and after cutting.

5.2. Design of the Control Scheme for the Hard Roof and Forced Mining to Press and Cut the Roof. The advanced presplitting blasting method is highly adaptable to the geological and technical conditions of the coal seam, has less impact on the normal mining of the working face, and requires less special equipment. The roof with better integrity is changed to a roof with artificial cracks, and the roof that is not easy to fall is changed to a roof that is easy to fall so as to reduce the suspended roof area of the goaf and eliminate pressure accumulation. In accordance with the specific geological conditions of the 11129 working face, a segmented deep hole presplitting blasting plan is adopted for the roof of the working face. The thick and hard sandstone direct-coated roof and the composite roof are at different distances from the cut holes in the two grooves. A 200-m retreat point is selected as the dividing line to design different roof deep hole blasting schemes. The blasting plan is divided into four steps: the first step is to blast in the cut hole to shorten the initial pressure step; the second step is to blast to the upper roof of the working face within a range of $200 \mathrm{~m}$ to solve the problem of large thick sandstone on the old roof on the composite roof; the third step is to blast the upper roof inside the working face within the range of $200 \mathrm{~m}$ to $700 \mathrm{~m}$ to solve the problem of thick sandstone direct overburden; and the fourth step is to blast in the axial direction of the groove to solve the problem of untimely falling of the upper and lower corner roofs. The cross-sectional view of the blast hole is shown in Figure 7.

Before installation of the working face support, deep hole blasting is performed for forced topping in the cut hole, as shown in Figure 7. The advantage of this scheme is that it does not affect production, can effectively cut the top plate, and shorten the initial pressure step. In the cut hole, holes are punched at a distance of $35 \mathrm{~m}$ from the coal wall at the lower end and $1.5 \mathrm{~m}$ from the goaf side coal bank with a hole 

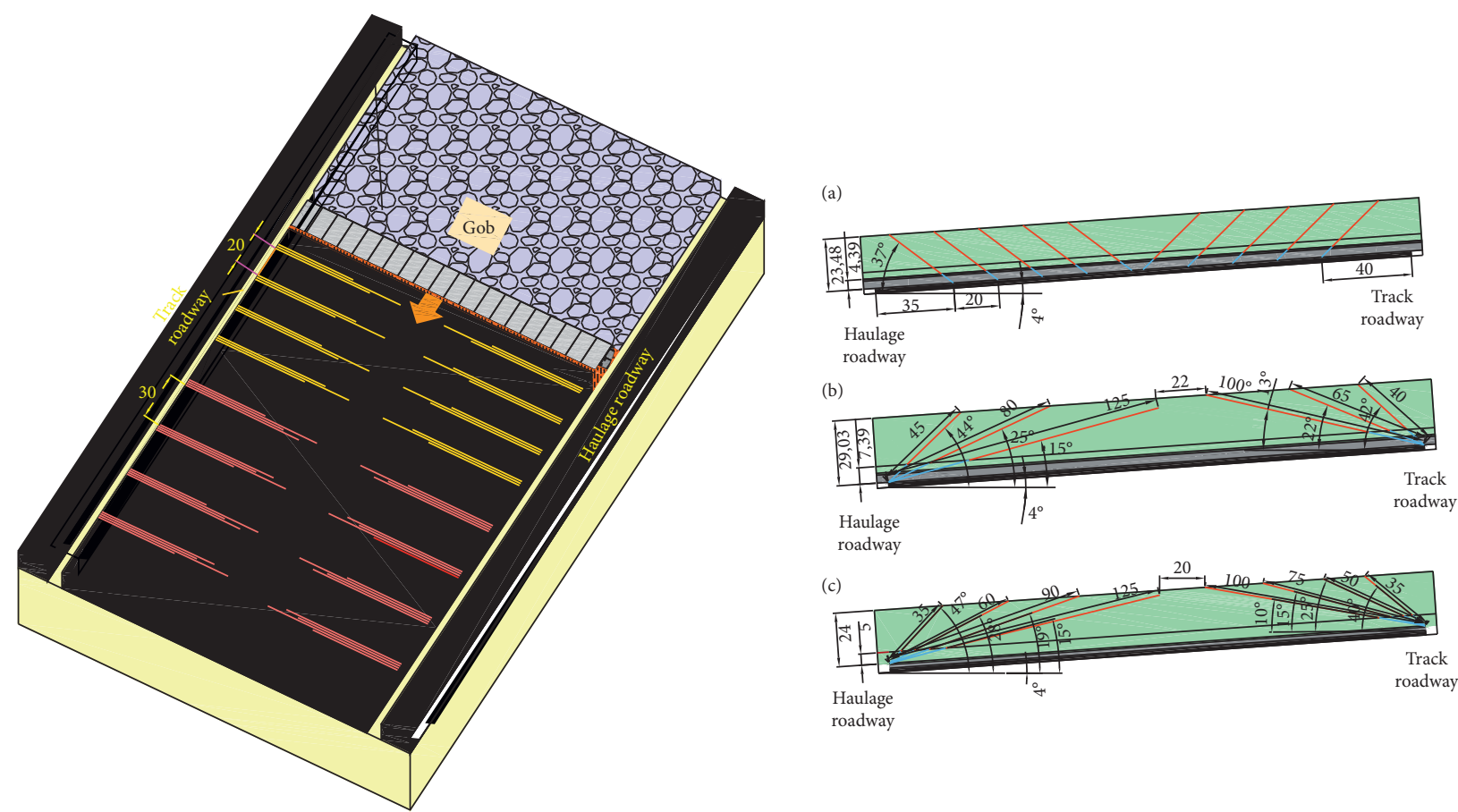

Figure 7: Layout of the blast holes in the working face of the stope.

spacing of $20 \mathrm{~m}$. Holes are punched at a distance of $40 \mathrm{~m}$ from the rail line and $1.5 \mathrm{~m}$ from the goaf side coal bank with a hole spacing of $20 \mathrm{~m}$.

The first group of blast holes are $12 \mathrm{~m}$ away from the coal wall of the cut hole within $200 \mathrm{~m}$ in front of the cut in the working face. The horizontal spacing of blast holes is $1.5 \mathrm{~m}$, the long and short holes are staggered, and the group spacing is $20 \mathrm{~m}$. Specifically, the distance between the first blast hole in the second group and the third blast hole in the first group is $20 \mathrm{~m}$. In the haulage roadway or track roadway, every two sets of blast hole exploration and charge are sealed, that is, six holes can be detonated at the same time. Deep hole loosening blasting is performed on the upper roof of the inner working face of the haulage roadway and the track roadway. In accordance with the roof collapse and the characteristics of the working face rock pressure, the working face is determined whether it is within $100 \mathrm{~m}$ from the cut-off coal wall. Deep hole loosening blasting is conducted on the upper roof of the working face. Affecting the gas drainage must be avoided because a high-drainage roadway is arranged at approximately $30 \mathrm{~m}$ above the roof of the coal seam and approximately $30 \mathrm{~m}$ away from the track roadway.

In the range of $200-700 \mathrm{~m}$ in front of the cut hole in the working face, the roof of the working face is mostly thick and hard sandstone directly covered roof. Deep hole loosening blasting is conducted on the upper roof of the working face every $30 \mathrm{~m}$ in the two troughs. This process is performed to make the roof of the working face controllable and ensure the normal and safe production of the working face. The horizontal spacing of the blast holes in the group is $1.5 \mathrm{~m}$, and the long and short holes are staggered. Affecting the gas drainage must be avoided because a high-drainage roadway is arranged at approximately $30 \mathrm{~m}$ above the roof of the coal seam and approximately $30 \mathrm{~m}$ away from the rail.

The roof is changed with better integrity to the artificial cracked roof through the combination of blasting on the roof of the cut-off hole, two-lane advanced deep hole blasting, and in-plane advanced deep hole blasting. The hard-to-fall huge sandstone roof fall section is made by sectioning after manual intervention, and the suspended roof area of the goaf is reduced. Pressure accumulation is eliminated, and the risk of roof fall during stoping and gas accumulation risks are reduced.

\section{Analysis of the Practical Effect of the Roof Cutting Project in the 11129 Working Face of Zhangji Mine}

6.1. Evaluation of Numerical Simulation Effect. A numerical model was established via the FLAC3D numerical simulation software, with the dimensions of $640 \mathrm{~m} \times 650 \mathrm{~m} \times 168 \mathrm{~m}$ (Figure 8). Drill holes into the roof of the 11129 working face to collect rock samples. The collected rock blocks are sealed and preserved with a plastic wrap to avoid water loss. The laboratory processes standard cylindrical rock samples of length $\times$ width $=100 \mathrm{~mm} \times 50 \mathrm{~mm}$. Use the MTS rock mechanical performance testing machine to test the mechanical properties of the rock sample and obtain the rock sample stress-strain curve. The elastic modulus can be solved by the slope. For the reliability of the data, the three lithology experiments of each group are averaged, and the mechanical parameters of the top and bottom plates are shown in Table 1. Fixed horizontal displacement constraints were set at 


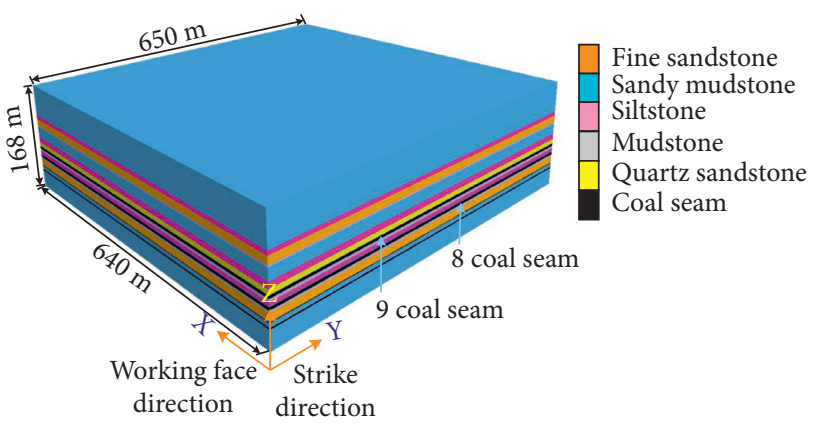

FIgURE 8: Three-dimensional numerical simulation model.

TABLE 1: Mechanical parameters of the roof and floor rock strata at the coal seam.

\begin{tabular}{|c|c|c|c|c|c|c|}
\hline Lithology & $\begin{array}{l}\text { Density } \\
\left(\mathrm{kg} / \mathrm{m}^{3}\right)\end{array}$ & $\begin{array}{l}\text { Bulk modulus } \\
(\mathrm{GPa})\end{array}$ & $\begin{array}{c}\text { Shear modulus } \\
(\mathrm{GPa})\end{array}$ & $\begin{array}{c}\text { Tensile strength } \\
(\mathrm{MPa})\end{array}$ & $\begin{array}{c}\text { Cohesion } \\
(\mathrm{MPa})\end{array}$ & $\begin{array}{c}\text { Internal friction angle } \\
\left(\left(^{\circ}\right)\right.\end{array}$ \\
\hline Sandy mudstone & 2605 & 2.16 & 1.69 & 0.38 & 2.6 & 27 \\
\hline Siltstone & 3211 & 10.48 & 8.19 & 0.44 & 2.85 & 28 \\
\hline $\begin{array}{l}\text { Quartz } \\
\text { sandstone }\end{array}$ & 2600 & 21.03 & 13.53 & 0.47 & 2.8 & 30 \\
\hline $9-2$ \# coal & 1300 & 0.83 & 0.38 & 0.29 & 1.8 & 24 \\
\hline Mudstone & 2554 & 3.23 & 1.85 & 0.32 & 2.2 & 28 \\
\hline 9-1 \# coal & 1300 & 0.83 & 0.38 & 0.29 & 1.8 & 24 \\
\hline Mudstone & 2554 & 3.23 & 1.85 & 0.32 & 2.2 & 28 \\
\hline Siltstone & 3211 & 10.48 & 8.19 & 0.44 & 2.85 & 28 \\
\hline Sandy mudstone & 2605 & 2.16 & 1.69 & 0.38 & 2.6 & 27 \\
\hline 8 \# coal & 1300 & 0.83 & 0.38 & 0.29 & 1.8 & 24 \\
\hline Mudstone & 2554 & 3.23 & 1.85 & 0.32 & 2.2 & 28 \\
\hline
\end{tabular}

the bottom edge, front, back, left, and right boundaries of the model. The Mohr-Coulomb failure criterion was also adopted to analyze the mechanical characteristics of coal and rock mass in this model. Domestic and foreign scholars have conducted several experiments and studies on the abutment effect of equivalent filled rock mass in goafs [28-31]. In the present study, the goaf was simulated with the double-yield model. The stress-strain relation of the rock mass in the goaf is presented in Table 2, and the mechanical parameters of the rock mass in the double-yield goaf are presented in Table 3.

The simulated 11129 working face advances along the strike (positive direction of the $y$-axis) from the cut-off cut, and the cut-off cut is $200 \mathrm{~m}$ away from the boundary to eliminate the influence of boundary effects. The excavation step is $20 \mathrm{~m}$, the goaf is backfilled and balanced, the direction is advanced by $260 \mathrm{~m}$, and the mining is stopped at $y=460 \mathrm{~m}$. During the stoping process, the pressure distribution of the stope before and after the top cut and the real-time working resistance changes in the supports at different positions are analyzed, as shown in Figures 9 and 10 .

As shown in Figure 9, a goaf is formed behind the working face and the stress is redistributed with the advancement of the working face. The center of the stope support bears the greatest force and gradually decreases to two sides of the working face, approximately showing a " $\wedge$ " change. A concentrated stress area is found around the goaf before the topping, where the maximum leading support pressure is $40 \mathrm{MPa}$ and the stress concentration factor is 2.1. After the roof is cut, the coal wall advances the supporting pressure zone forward, forming a small local stress concentration between the blocks. A large stress concentration area is formed in the front before cutting the roof section. The influence range of the lateral support pressure in the goaf area increases after the roof is cut, and the maximum stress is $40 \mathrm{MPa}$.

As shown in Figure 10, compare and analyze the changes in the working resistance of the stope support before and after roof cutting when the support is at different distances from the coal wall; the real-time working resistance of the support before and after the top-cutting gradually increases with the mining (number of steps) of the working face and finally stabilizes. The support is at the minimum control distance $(5275 \mathrm{~mm})$, and the end resistance of the support before and after the topping is 5436 and $3235 \mathrm{kN}$, respectively. After the roof cutting, the working resistance of the stope support is obviously improved, and the pressure is reduced by $40.5 \%$ on average; the stent is at the maximum control distance $(6175 \mathrm{~mm})$, the end resistance of the stent before and after the roof cutting is 7108 and $4126 \mathrm{kN}$ respectively, and the pressure is reduced by $42 \%$ on average. Effective roof cutting measures under hard roof conditions can help improve the working environment of stope supports and ensure safe and efficient mining at the 11129 working face. 
TABLE 2: Stress-strain relation of rock mass in the double-yield model goaf.

\begin{tabular}{lccccc}
\hline Strain & Stress $(\mathrm{MPa})$ & Strain & Stress $(\mathrm{MPa})$ & Strain & Stress $(\mathrm{MPa})$ \\
\hline 0.01 & 0.37 & 0.07 & 4.00 & 0.13 & 0.14 \\
0.02 & 0.79 & 0.08 & 5.01 & 0.15 & 21.2 \\
0.03 & 1.26 & 0.09 & 6.25 & 0.16 & 29.7 \\
0.04 & 1.80 & 0.10 & 7.79 & 0.17 & 45.7 \\
0.05 & 2.42 & 0.11 & 9.75 & & 87.5 \\
0.06 & 3.15 & 0.12 & 12.3 & & \\
\hline
\end{tabular}

TABle 3: Mechanical parameters of main rock materials in the goaf.

\begin{tabular}{lccccc}
\hline Category & Density $\left(\mathrm{kg} / \mathrm{m}^{3}\right)$ & Bulk modulus $(\mathrm{GPa})$ & Shear modulus $(\mathrm{GPa})$ & Internal friction angle $\left({ }^{\circ}\right)$ & Dilatancy angle $\left({ }^{\circ}\right)$ \\
\hline Value & 2000 & 11.1 & 8.3 & 13 & 7 \\
\hline
\end{tabular}

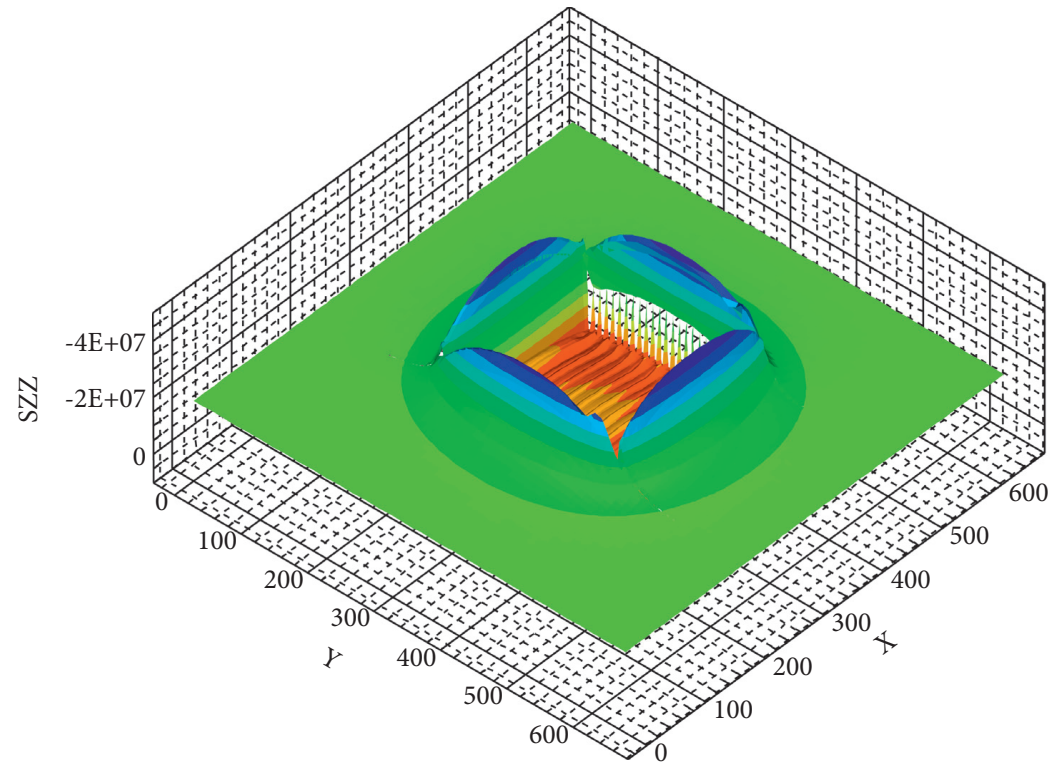

(a)

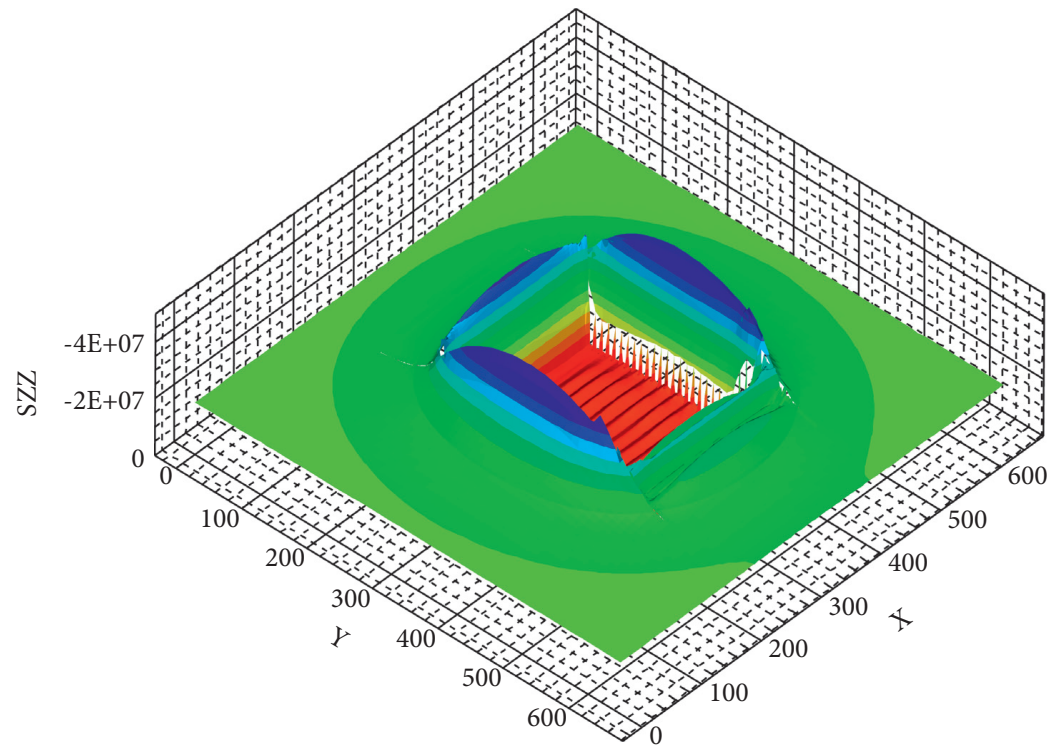

(b)

\section{SZZ}

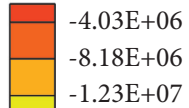

$-1.23 \mathrm{E}+07$

$-1.65 \mathrm{E}+07$

$-2.06 \mathrm{E}+07$

$-2.48 \mathrm{E}+07$

$-2.89 \mathrm{E}+07$

$-3.31 \mathrm{E}+07$

$-3.73 \mathrm{E}+07$

$-4.14 \mathrm{E}+07$

$-4.56 \mathrm{E}+07$

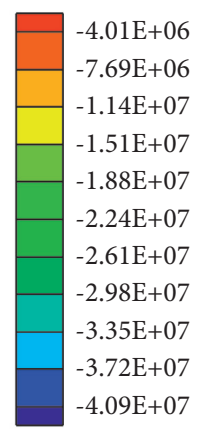

FIGURE 9: Curve of stress change of surrounding rock $5 \mathrm{~m}$ from support to coal wall. (a) Before cutting the roof. (b) After cutting the roof. 


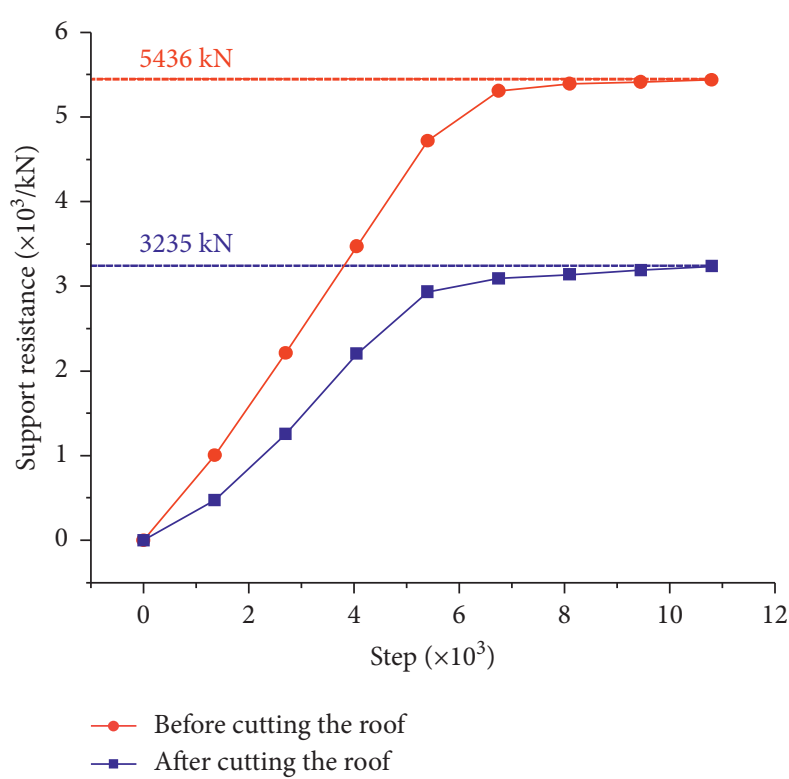

(a)

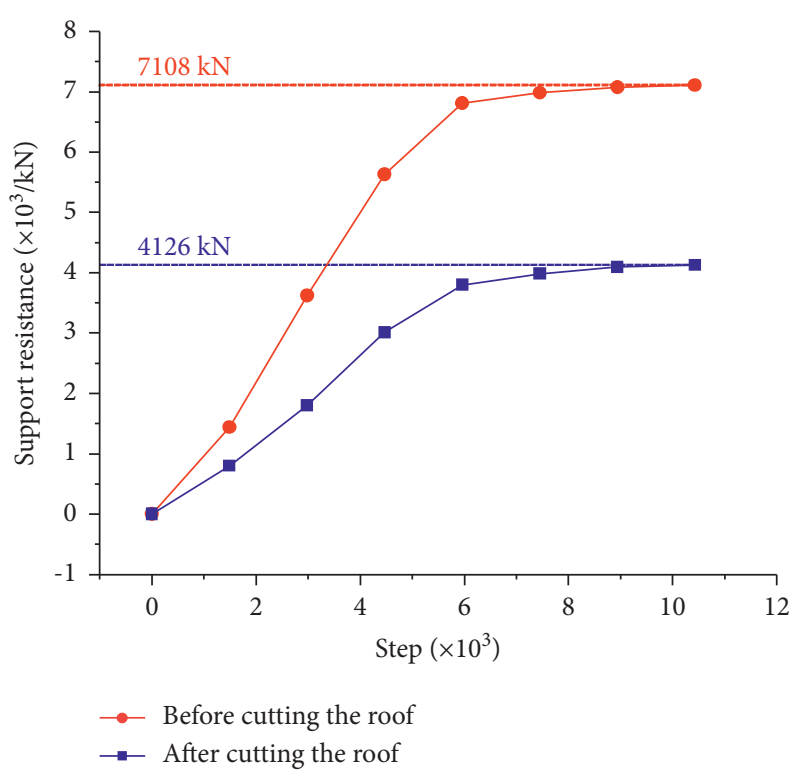

(b)

FIGURE 10: Curves of the working resistance of the support before and after the top cut. (a) Distance of $5.275 \mathrm{~m}$ from the support to the coal wall. (b) Distance of $6.175 \mathrm{~m}$ from the support to the coal wall.

6.2. Engineering Practice Effect Feedback. The roof support of the 11129 working face of Zhangji Mine adopts ZZ10800/18/ $38 \mathrm{D}$ type support shield type support, and the support strength is $1.39-1.5 \mathrm{MPa}$. The support center distance is $1500 \mathrm{~mm}$, the top beam length is $5275 \mathrm{~mm}$, and the frame moving step distance is $800 \mathrm{~mm}$. The topping plan was implemented within the range of $175 \mathrm{~m}$ from the cutting eye at the project site, and the working resistance of the support was compared and analyzed with the subsequent range of 175-300 $\mathrm{m}$ without topping. In accordance with the original cyclic resistance curve of the working face support, combined with the roof deep hole blasting parameters and the daily cutting and retracting conditions of the working face, the specific pressure curve change law of the hydraulic support is selected for analysis.

The ore compaction measurement during the production period shows that the initial pressure step distance of the different sections of the working face is $40.08 \mathrm{~m}$ (excluding the width of the open cut). During the compression period, the average dynamic load coefficient is 1.3-1.5. During the mining face, the time-weighted resistance of each observation support is $2514-3521 \mathrm{kN}$, accounting for $23.3 \%$ $32.6 \%$ of the rated working resistance. The end-of-circulation resistance is $3892-4521 \mathrm{kN}$, accounting for $36.4 \%-$ $41.9 \%$ of the rated working resistance.

The actual measured curves of the real-time working resistance of the support before and after the top-cutting observation of working faces $\# 40, \# 60, \# 70$, and \#140 are shown in Figure 11.

The measured data of the pressure changes of the \#40, $\# 60$, \#70, and \#140 supports in the 11129 working face are selected for research. The \#40 support is located at the lower part of the 11129 working face; the average end resistance of the support before and after the top is 4736 and $4197 \mathrm{kN}$, respectively. Compared with other parts, the pressure of the support is relatively small. The reason is that the support is located at the end of the stope, the end of the roof is bent and sinks less, and the force transmitted to the support is relatively small. The \#60 and \#70 supports are located in the middle of the working face of the stope, and the resistance at the end of the support before the top cut is 5006 and $5693 \mathrm{kN}$, respectively. The deflection of the middle part of the roof changes the most, and the force acting on the support is relatively large. The end resistance of the support is significantly reduced after the top is cut in the working face. The average end resistance of the \#60 and \#70 supports are reduced by $29.8 \%$ and $38.6 \%$, respectively. Field data prove that the implementation of presplitting blasting can effectively improve the force of stope supports. The \#140 bracket is also located at the end of the working surface, and the average end resistance is higher than that of the \#40 bracket. The reason is that the \#140 support is closer to the track along the trough, the track along the trough is more simplified than the transportation along the trough, and the force acting on the stope support is slightly larger than the lower support. In the early stage of mining, no abnormalities, such as slabs, roof leakage, and water splashing on the coal wall, are found in accordance with on-site observations. In the normal mining stage, the opening rate of the support safety valve after roof cutting is less than $5 \%$, the coal wall integrity is good, and has no major impact on the mining process. The roof cutting effect is good, and the support working resistance meets the control requirements of the surrounding rock of the stope. 


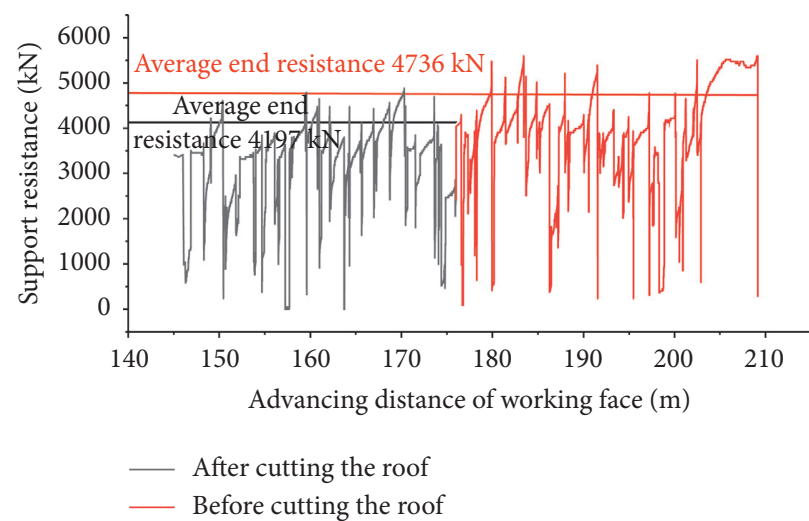

(a)

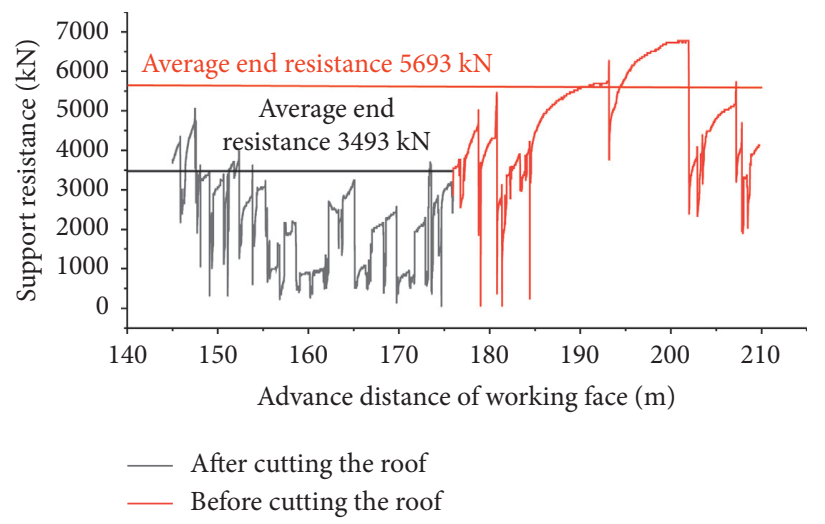

(c)

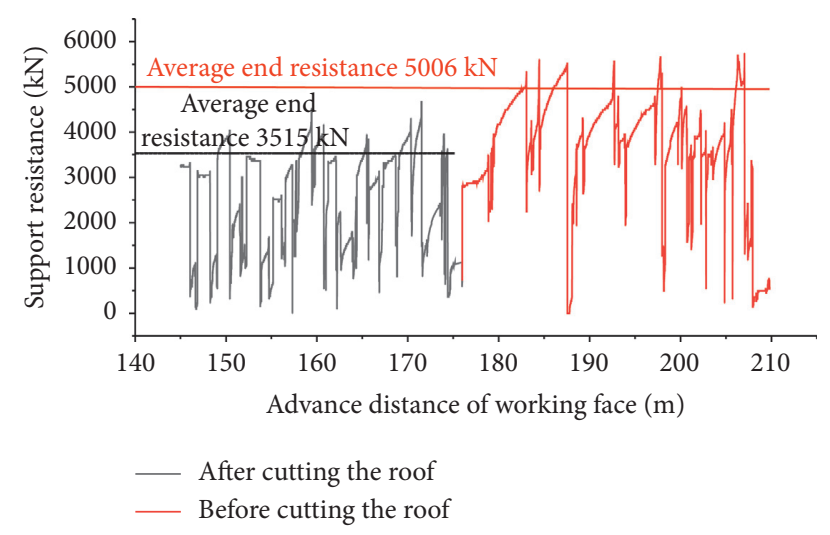

(b)

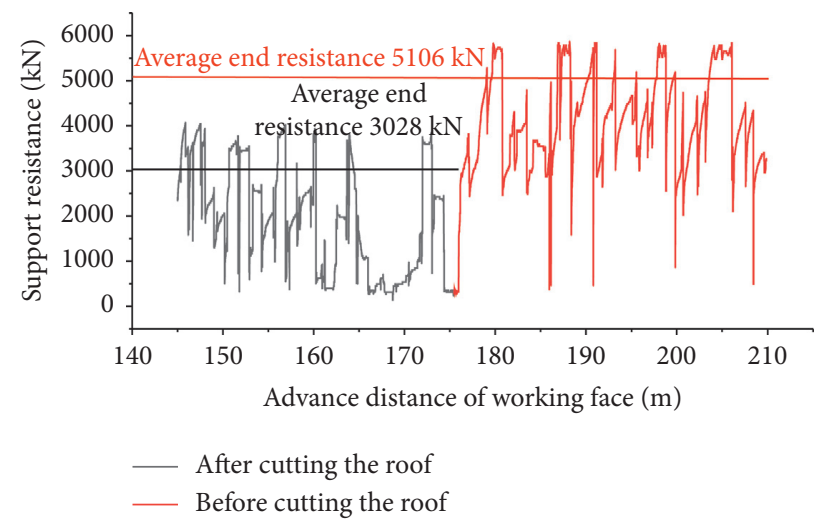

(d)

Figure 11: Measured curve of stent resistance. (a) No. 40 observation support. (b) No. 60 observation support. (c) No. 70 observation support. (d) No. 140 observation support.

\section{Conclusions}

(1) A mechanical model of the interaction between the cantilever beam of the hard roof of the stope and the support during periodic breakage is established. The force distribution equations under different distances from the support to the coal wall are obtained. The theoretical value is slightly larger than the numerical simulation and the actual measurement site. The reason is that the theoretical calculation simplifies the mechanical model and does not consider the bearing capacity of the overlying rock. The overlying rock bears a certain self-weight load in the field, which reduces the force acting on the support.

(2) The load-bearing stability of the support is significantly affected by factors, such as buried depth $\mathrm{H}$, elastic modulus of the roof itself, thickness $h$, and roof cantilever length $l_{0}$. However, most of the influencing factors belong to the geological conditions of the coal seam itself. In the actual mining process, understanding the engineering geological parameters of the working face and evaluating the degree of change in the work resistance of the support and its safety and stability are necessary.
(3) The advanced presplit blasting can effectively destroy the integrity of the roof itself and reduce the periodic breaking distance, thereby improving the apparent problems of the roof rock pressure and reducing the load on the support of the working face. The measured results show that the average end resistance of the support before and after roof cutting is reduced from $5235.25 \mathrm{kN}$ to $3558.25 \mathrm{kN}$, reducing the bearing capacity of the support by $30.7 \%$. The pressure distribution of the hydraulic support in the numerical simulation stope is approximately " $\Lambda$ " in the middle and lower sides. The simulated value is slightly smaller than the theoretical calculation value. This finding is because the goaf is backfilled during the simulation process, and the roof has a certain ability to bear the load.

(4) The 11129 working face is the first coal mining face of group B in the central area of Zhangji Mine. In accordance with the specific geological environment of the working face, the cut-off plan for the cut hole and the concrete presplitting blasting along the groove are given. Deep hole presplitting blasting is conducted to reduce the risk of mining and provide experience for the subsequent mining of group $B$ coal in the later period. 


\section{Data Availability}

All data generated or analyzed during this study are included in this published article.

\section{Conflicts of Interest}

The authors declare no conflicts of interest.

\section{Authors' Contributions}

Jiaxin Dang and Qingwei Bu conducted theoretical calculation and analysis; Jiaxin Dang, Min Tu, and Xiangyang Zhang perfromed field data collection; Jiaxin Dang and Qingwei Bu conducted numerical simulation analysis; and Jiaxin Dang wrote the manuscript.

\section{Acknowledgments}

This research was funded by the Anhui Collaborative University Innovation Project (GXXT-2020-056) and the National Natural Science Foundation of China (52074008, 52074007, and 52104114).

\section{References}

[1] D. Z. Kong, S. L. Yang, L. Gao, and Z.-Q. Ma, "Determination of support capacity based on coal face stability control," Journal of the China Coal Society, vol. 42, no. 3, pp. 590-596, 2017.

[2] A. Mangal and P. S. Paul, "Rock mechanical investigation of strata loading characteristics to assess caving and requirement of support resistance in a mechanized powered support longwall face," International Journal of Mining Science and Technology, vol. 26, no. 6, pp. 1081-1087, 2016.

[3] S. Prusek, M. Płonka, and A. Walentek, "Applying the ground reaction curve concept to the assessment of shield support performance in longwall faces," Arabian Journal of Geosciences, vol. 9, no. 3, p. 167, 2016.

[4] R. Trueman, G. Lyman, M. Callan, and B. Robertson, "Assessing longwall support-roof interaction from shield leg pressure data," Mining Technology, vol. 114, no. 3, pp. 176-184, 2005.

[5] S. Yang, G. Song, and D. Kong, "An evaluation of longwall face stability in thick coal seams through a basic understanding of shield-strata interaction," Journal of Geophysics and Engineering, vol. 16, no. 1, pp. 125-135, 2019.

[6] J. Wang, Y. Yuan, T. Shihao, and B. Li, "Roof structure characteristics in fully mechanized coalface with large mining height and reasonable loading of support," Journal of Mining \& Safety Engineering, vol. 31, no. 4, pp. 512-518, 2014.

[7] Z. Wang, J. Wang, Y. Yang, Y Tang, and L Wang, "Mechanical relation between support stiffness and longwall face stability within fully-mechanized mining faces," Journal of China University of Mining and Technology, vol. 48, no. 2, pp. 258-267, 2019.

[8] G. F. Wang, Y. H. Pang, M. Z. Li, Y. Ma, and X.-H. Liu, "Hydraulic support and coal wall coupling relationship in ultra large height mining face," Journal of the China Coal Society, vol. 42, no. 2, pp. 518-526, 2017.

[9] Y. Pang, G. Wang, and Q. Yao, "Double-factor control method for calculating hydraulic support working resistance for longwall mining with large mining height," Arabian Journal of Geosciences, vol. 13, no. 6, 2020.

[10] Q. Bai, S. Tu, Z. Li, and H. Tu, "Theoretical analysis on the deformation characteristics of coal wall in a longwall top coal caving face," International Journal of Mining Science and Technology, vol. 25, no. 2, pp. 199-204, 2015.

[11] S. K. Das, "Observations and classification of roof strata behaviour over longwall coal mining panels in India," International Journal of Rock Mechanics and Mining Sciences, vol. 37, no. 4, pp. 585-597, 2000.

[12] J. Lou, H. Kang, F. Gao, J. Yang, and J. Li, "Determination of large-height support resistance based on multi-factor analysis," Journal of China Coal Society, vol. 42, 2017.

[13] X. Yin, "Double period dynamic mechanism of support and sur-rounding rock in fully mechanized mining face," Journal of China Coal Society, vol. 42, 2017.

[14] Q. Wang, M. He, S. Li et al., "Comparative study of model tests on automatically formed roadway and gob-side entry driving in deep coal mines," International Journal of Mining Science and Technology, vol. 31, no. 4, pp. 591-601, 2021.

[15] Q. Wang, Y. Wang, M. He et al., "Experimental research and application of automatically formed roadway without advance tunneling," Tunnelling and Underground Space Technology, vol. 114, Article ID 103999, 2021.

[16] Q. Yin, J. Wu, C. Zhu, M. He, Q. Meng, and H. Jing, "Shear mechanical responses of sandstone exposed to high temperature under constant normal stiffness boundary conditions," Geomechanics and Geophysics for Geo-Energy and GeoResources, vol. 7, no. 2, p. 35, 2021.

[17] C. Zhu, M. C. He, X. H. Zhang, Z. G Tao, Q Yin, and L.-F. Li, "Nonlinear mechanical model of constant resistance and large deformation bolt and influence parameters analysis of constant resistance behavior," Rock and Soil Mechanics, vol. 42, no. 7, pp. 1911-1924, 2021.

[18] X. Li, K. Peng, J. Peng, and D. Hou, "Experimental investigation of cyclic wetting-drying effect on mechanical behavior of a medium-grained sandstone," Engineering Geology, vol. 293, Article ID 106335, 2021.

[19] Z. Tao, Y. Shu, X. Yang, Y. Peng, Q. Chen, and H. Zhang, "Physical model test study on shear strength characteristics of slope sliding surface in Nanfen open-pit mine," International Journal of Mining Science and Technology, vol. 30, no. 3, pp. 421-429, 2020.

[20] X. Li, K. Peng, J. Peng, and H. Xu, "Effect of cyclic wettingdrying Treatment on strength and failure behavior of two quartz-Rich sandstones under direct shear," Rock Mechanics and Rock Engineering, vol. 6, 2021.

[21] F. Wu, H. Zhang, Q. Zou, C. Li, J. Chen, and R. Gao, "Viscoelastic-plastic damage creep model for salt rock based on fractional derivative theory," Mechanics of Materials, vol. 150, Article ID 103600, 2020.

[22] W. Pan, X. Wang, Q. Liu, Y. Yuan, and B. Zuo, "Non-parallel double-crack propagation in rock-like materials under uniaxial compression," International Journal of Coal Science \& Technology, vol. 6, no. 3, pp. 372-387, 2019.

[23] Y. Wang, B. Zhang, B. Li, and C. Li, "A strain-based fatigue damage model for naturally fractured marble subjected to freeze-thaw and uniaxial cyclic loads," International Journal of Damage Mechanics, vol. 30, no. 9, pp. $105678952110216-$ 105678952111323, 2021.

[24] Y. Zhao, H. Zhou, J. Zhong, and D. Liu, "Study on the relation between damage and permeability of sandstone at depth under cyclic loading," International Journal of Coal Science \& Technology, vol. 6, no. 4, pp. 479-492, 2019. 
[25] F. K. Xiao, L. Q. Duan, and Z. H. Ge, "Laws of floor breaking in coal mining face and gas extraction application," Journal of China Coal Society, vol. 35, no. 3, pp. 417-419, 2010.

[26] X. R. Meng, C. H. Xu, Z. N. Gao, and X.-Q. Wang, "Stress distribution and damage mechanism of mining floor," Journal of China Coal Society, vol. 35, no. 11, pp. 1832-1836, 2010.

[27] X. U. Gang, "Experimental and theoretical study on hydraulic support in working face and its relationship with roof subsidence," Journal of China Coal Society, vol. 40, 2015.

[28] M. Shabanimashcool and C. C. Li, "Numerical modelling of longwall mining and stability analysis of the gates in a coal mine," International Journal of Rock Mechanics and Mining Sciences, vol. 51, pp. 24-34, 2012.

[29] D. N. Whittles, I. S. Lowndes, S. W. Kingman, C. Yates, and S. Jobling, "Influence of geotechnical factors on gas flow experienced in a UK longwall coal mine panel," International Journal of Rock Mechanics and Mining Sciences, vol. 43, no. 3, pp. 369-387, 2006.

[30] Z. Zhang, J. Bai, Y. Chen, and S. Yan, "An innovative approach for gob-side entry retaining in highly gassy fullymechanized longwall top-coal caving," International Journal of Rock Mechanics and Mining Sciences, vol. 80, pp. 1-11, 2015.

[31] H. Yavuz, "An estimation method for cover pressure re-establishment distance and pressure distribution in the goaf of longwall coal mines," International Journal of Rock Mechanics \& Mining Sciences, vol. 41, no. 2, 2004. 